\title{
THE LEFT PARASTERNAL IMPULSE
}

\author{
BY \\ P. M. S. GILlAM, A. A. DELIYANNIS, AND J. P. D. MOUNSEY \\ From the Department of Medicine and the M.R.C. Cardiovascular Research Group, Postgraduate Medical School, \\ Hammersmith Hospital, London W.12
}

Received April 26, 1964

A lift or heave which is palpable at the left sternal edge is an accepted clinical sign of right ventricular hypertrophy. The parasternal impulse has been recorded in normal subjects and in patients with heart disease, and the results are described in this paper. A detailed description of the instrument used to make the recordings has already been published (Beilin and Mounsey, 1962). This instrument records absolute displacement of a selected area on the chest wall. By correlating the recordings with clinical examination, chest radiographs, electrocardiograms, and the results of right heart catheterization, we have been able to define, in terms of displacement, the characteristics that distinguish normal from abnormal impulses. We have also attempted to assess the reliability of an abnormal impulse in revealing underlying ventricular and atrial hypertrophy.

\section{SubJECTS AND METHODS}

The impulse cardiogram was recorded with the patient lying on a couch in the semi-recumbent position, with the breath held in expiration. The recording instrument consists essentially of a brass rod with a small button $3 \mathrm{~mm}$. in diameter at one end, which is placed on the chest wall and moved up and down by the cardiac impulse. Movement of the rod interrupts a beam of light on a photoelectric cell: this varies the resistance in an electrical circuit, the current from which is fed into the extra low frequency galvanometer of a Cambridge phonocardiograph. The recording system was arranged so that $1 \mathrm{~mm}$. of movement of the chest wall produced a $5 \mathrm{~cm}$. deflection in the impulse cardiogram. A simultaneous electrocardiogram and phonocardiogram were recorded as reference tracings.

The left parasternal impulse was recorded at the site of greatest pulsation. In some patients this was in the third or fourth intercostal space; in others the fourth, fifth, and sixth costal cartilages were so close together that the knob of the recorder was placed on top of them. The exact site of the left parasternal impulse was recorded in each case. The apical impulse was also recorded routinely in all cases.

Twenty normal subjects and 71 patients with heart disease were studied. Of the 20 normal subjects, 6 were volunteers from among the medical staff, and 14 were patients with clinically normal hearts. There were 14 males and 6 females, 3 of whom were children; their ages varied from 5 to 52 years. Of the 71 patients, 9 had pulmonary stenosis, 4 had Fallot's tetralogy, 8 had atrial septal defect, 15 had ventricular septal defect, and 1 had a patent ductus arteriosus; 8 patients had mitral stenosis and 14 mitral incompetence; 1 had primary pulmonary hypertension, and 1 pulmonary hypertension resulting from chronic bronchitis and emphysema; 10 patients were suffering from cardiomyopathy. There were 28 males and 43 females, 12 of whom were children; their ages varied from 5 to 70 years. In all patients a full 14-lead electrocardiogram, and posteroanterior and lateral chest radiographs were used for the assessment of right ventricular hypertrophy. The electrocardiographic criteria employed were those of Goodwin and Abdin (1959). Confirmation of the diagnosis was obtained in 61 of the patients by cardiac catheterization. Angiocardiograms were available in 42 of the cases. 


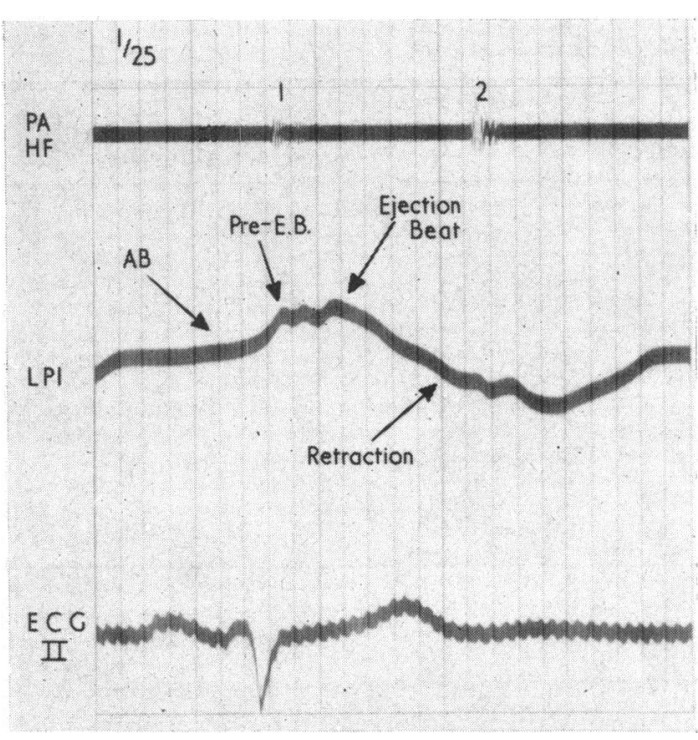

FIG. 1.-The left parasternal impulse (LPI) in health. Gentle outward movement during atrial systole (AB). Pre-ejection beat (Pre-E.B.) followed by ejection beat. Systolic retraction in last third of systole. PA, $\mathrm{HF}=$ phonocardiogram, high frequency; 1 and 2 =first and second heart sounds; $\mathbf{E C G}=$ electrocardiogram lead II.

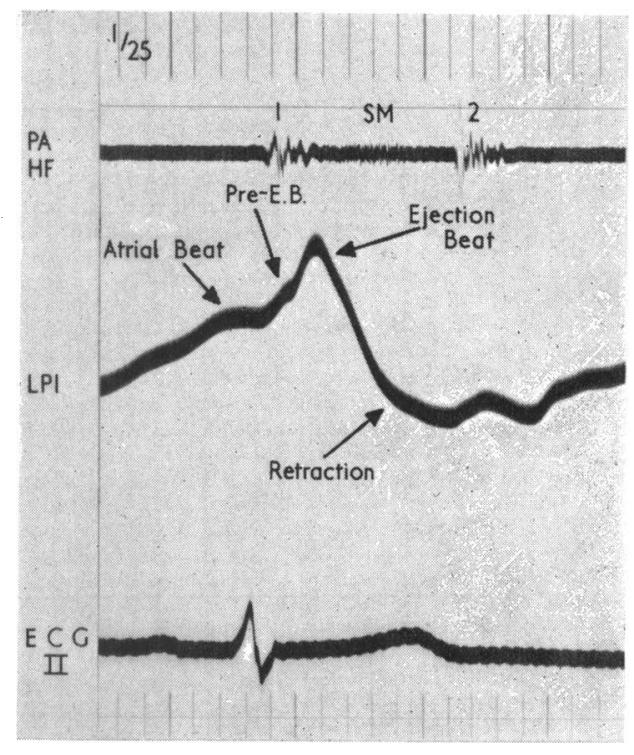

Fig. 2.-Overacting left parasternal impulse (LPI) in depressed sternum with normal heart. Abnormally tall, peaked ejection beat, followed by systolic retraction in last third of systole. Large atrial beat. Clear pre-ejection beat (Pre-E.B.). PA, HF = phonocardiogram, high frequency; 1 and $2=$ first and second heart sounds; $\mathbf{S M}=$ systolic murmur; ECG =electrocardiogram lead II.

\section{RESULTS}

\section{Left Parasternal Impulse in Health}

Movements of the præcordium at the left sternal edge accompanying the heart beat are always present in the normal subject. These movements are often less easy to feel than is the apical impulse. This is because they are smaller and because they consist of an antero-posterior movement of a wide area of the præcordium rather than an independent movement of a localized area in an intercostal space.

In 14 of the normal subjects there was an outward movement of the chest wall in the left parasternal area during early systole, followed by retraction in late systole (Fig. 1). In 6 an inward movement only occurred. As in the apical impulse cardiogram in health (Beilin and Mounsey, 1962) it was possible to recognize two small outward beats in early systole, a pre-ejection beat starting after the $Q$ wave and before the first heart sound, and an ejection beat starting about $0 \cdot 1$ sec. after the $Q$ wave. Eight subjects had both types of beat, 2 had pre-ejection beats only, and 4 had ejection beats only. The amplitude of the beats was small in 11 of the subjects, producing a deflection in the impulse cardiogram of $7 \mathrm{~mm}$. or less. Impulses of considerable amplitude were recorded in the other three subjects, two of whom were children aged 5 and one a boy of 16 with a depressed sternum. In the children, the ejection beat measured 9 and $12 \mathrm{~mm}$. in amplitude, while in the boy it was particularly large and measured $19 \mathrm{~mm}$. (Fig. 2). The average deflection in the impulse cardiogram in the 14 subjects with outward chest movements was $3.6 \mathrm{~mm}$. (When there was both a pre-ejection beat and an ejection beat the larger of the two was measured.) In none of the normal subjects did the outward movement last for more than the first two-thirds of systole. The average length of the systolic beat was $0.15 \mathrm{sec}$,, compared with an average length of systole of $0.33 \mathrm{sec}$. 
TABLE I

Pulmonary Stenosis

\begin{tabular}{|c|c|c|c|c|c|}
\hline Case No. & $\begin{array}{l}\text { R.V. pressure } \\
\text { (mm. Hg) }\end{array}$ & $\begin{array}{l}\text { P.A. pressure } \\
\text { (mm. Hg) }\end{array}$ & $\begin{array}{c}\text { Chest } \\
\text { radiography }\end{array}$ & Electrocardiogram & $\begin{array}{l}\text { Left parasternal } \\
\text { impulse }\end{array}$ \\
\hline $\begin{array}{l}1 \\
2 \\
3 \\
4 \\
5 \\
6\end{array}$ & $\begin{array}{l}28 / 0 \\
29 / 5 \\
32 / 3 \\
55 / 0-8 \\
55 / 7 \\
62 / 0\end{array}$ & $\begin{array}{l}-\overline{20 / 8} \\
19 / 10 \\
12 / 6 \\
34 / 12 \\
32 / 10\end{array}$ & $\begin{array}{l}\text { P.A.+ } \\
\text { Normal } \\
\text { P.A.+ } \\
\text { P.A.+ } \\
\text { P.A.+ } \\
\text { P.A.+ }\end{array}$ & $\begin{array}{l}\text { Borderline normal } \\
\text { Normal } \\
\text { Normal } \\
\text { R.V.H. Grade I } \\
\text { R.V.H. Grade II } \\
\text { R.V.H. Grade II }\end{array}$ & $\begin{array}{l}\text { Normal } \\
\text { Normal } \\
\text { Normal } \\
\text { Normal } \\
\text { Sustained } \\
\text { Sustained }\end{array}$ \\
\hline 7 & $96 / 0$ & $22 / 11$ & P.A.t & R.V.H. Grade I & Sustained \\
\hline 8 & $120 / 0-4$ & - & P.A.t & R.V.H. Grade II & Normal \\
\hline 9 & $125 / 8$ & - & $\begin{array}{l}\text { R.v. } \\
\text { R.V.t }\end{array}$ & R.V.H. Grade II & Sustained \\
\hline
\end{tabular}

R.V.H., right ventricular hypertrophy.

In 6 of the impulse cardiograms there was an outward movement, between the start of the P wave and the $Q$ wave in the electrocardiogram, constituting the atrial beat, which accompanied atrial systole (Fig. 1 and 2). The tallest atrial beat seen in health was $5 \mathrm{~mm}$. high.

The left parasternal impulse cardiograms were compared with those recorded at the apex in these normal subjects. The apical impulse was larger than the corresponding parasternal one. There were minor differences in the pattern of the impulses at the two places, but these were not the same from one subject to another. When an atrial beat was present it was relatively larger in the parasternal area. As already mentioned, there were 6 subjects with inward movement only at the left sternal edge: these had a normal outward apical impulse. In the other 14 subjects the timing of the start of the ejection beat was delayed by an average of $3 / 100$ ths of a second at the left sternal edge; the average timing of the pre-ejection beats in relation to the electrocardiogram was identical at the two sites.

\section{Left Parasternal Impulse in Right Ventricular Hypertrophy}

The patients will be considered in two main groups: first those whose disease causes lone or dominant right ventricular hypertrophy, and secondly those whose disease causes biventricular hypertrophy.

\section{Group 1: Right ventricular hypertrophy.}

(a) Pulmonary Stenosis. Of the 9 patients with this lesion (Table I), 5 had a normal impulse at the left sternal edge. Of these 5, 3 had mild stenosis, with right ventricular pressures of less than $35 \mathrm{mg}$. $\mathrm{Hg}$, and no evidence of right ventricular hypertrophy in the chest radiographs and electrocardiograms; 2 , however, had right ventricular hypertension and hypertrophy. The other 4 patients had impulses that differed from the normal in that the outward movement during systole lasted up to or beyond the second heart sound (Fig. 3). This type of impulse will be referred to as the sustained impulse. These patients all had severe stenosis with radiographic and electrocardiographic evidence of right ventricular hypertrophy.

Of the 9 patients with pulmonary stenosis 7 had an atrial beat (Fig. 3), which was thus a more frequent finding than in the normal subject, reflecting associated right atrial hypertrophy.

(b) Atrial Septal Defect. There were 5 patients with a secundum defect and 3 with an ostium primum. One of them was rather tall and thin, but none had any of the stigmata of Marfan's syndrome, and none had a depressed sternum. Fig. 4 shows the impulse cardiograms in these patients in relation to their pulmonary systemic flow ratios and right ventricular pressures. In 2 


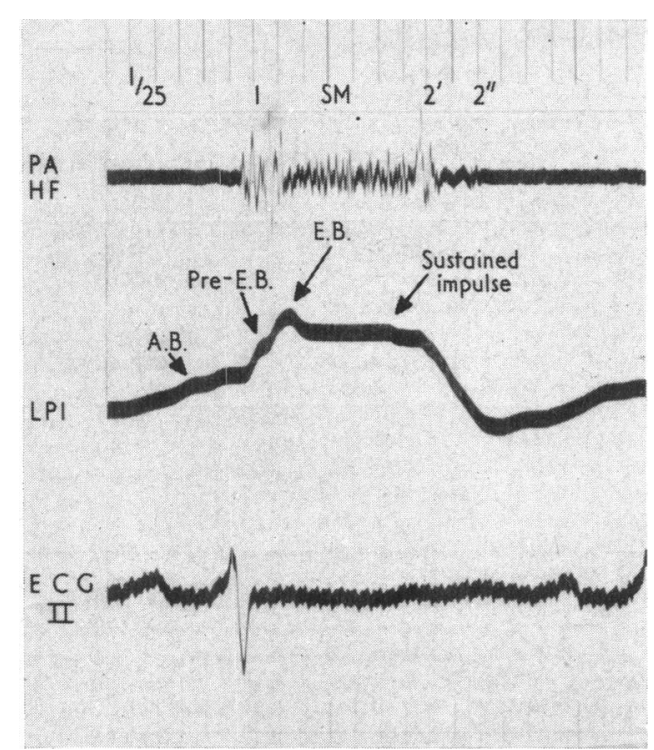

FIG. 3.-Sustained left parasternal impulse (LPI) in severe pulmonary stenosis $(P A P=24 / 11: R V P=$ $96 / 0 \mathrm{~mm}$. Hg). Outward systolic impulse sustained up to the aortic 2 nd sound ( $\left.2^{\prime}\right)$, with inward movement at the time of the delayed pulmonary 2nd sound (2"). Atrial beat (AB), pre-ejection beat (Pre-E.B.), and ejection beats (E.B.) shown. PA, $\mathrm{HF}=$ phonocardiogram, high frequency; SM=systolic murmur; ECG II=electrocardiogram lead II.

(Cases 3 and 6) the impulse was normal; in 5 (Cases 1, 2, 4, 5, and 7) it was of considerable amplitude but of normal contour, and this type of impulse, which resembles that recorded in a normal boy with a depressed sternum (Fig. 2), will be referred to as the overacting impulse. In one the impulse was sustained (Case 8). Only one patient had severe right ventricular hypertension; the remainder had an increased flow through the right ventricle but a normal or only moderately raised pressure. All the patients had enlargement of the right ventricle in the chest radiograph, but in the electrocardiogram only the patient with considerable pulmonary hypertension had evidence of severe right ventricular hypertrophy (Goodwin and Abdin, 1959, Grade I): the remainder showed incomplete right bundle-branch block. Thus in atrial septal defect an overacting impulse was common, reflecting the increased right ventricular stroke output, though a normal impulse did not exclude a considerable shunt. A sustained impulse was observed only in the patient with pulmonary hypertension and right ventricular hypertrophy. An additional abnormality in the impulse cardiogram of atrial septal defect was the increased frequency of an atrial beat which was seen in 6 of the 8 patients.

(c) Tetralogy of Fallot. Of the 4 patients with this condition all had severe right ventricular hypertrophy in the electrocardiogram (Table II); 2 were acyanotic at rest, while 2 were deeply cyanosed. Three of these cases had a sustained left parasternal impulse; the fourth, in spite of a right ventricular pressure of $120 / 7 \mathrm{~mm}$. $\mathrm{Hg}$, had a normal impulse.

(d) Mitral Stenosis. Of the 8 patients with dominant mitral stenosis (Table III), 4 had pure 
TABLE II

FaLLOT'S TETRALOGY

\begin{tabular}{c|c|c|c|c|c}
\hline Case No. & $\begin{array}{c}\text { R.V. pressure } \\
(\mathrm{mm} . \mathrm{Hg})\end{array}$ & $\begin{array}{c}\mathrm{Hb} \\
(\mathrm{g} . / 100 \mathrm{ml})\end{array}$ & $\begin{array}{c}\text { Arterial } \mathbf{O}_{2} \\
\text { saturation (\%) }\end{array}$ & Electrocardiogram & $\begin{array}{c}\text { Left parasternal } \\
\text { impulse }\end{array}$ \\
\hline 1 & $105 / 15$ & $17 \cdot 5$ & 91 & R.V.H. Grade II & Normal \\
2 & $110 / 5$ & 15 & 93 & $\begin{array}{c}\text { R.V.H. Grade II; } \\
\text { partial R.B.B.B. }\end{array}$ & Sustained \\
3 & $120 / 7$ & 24 & 68 & $\begin{array}{c}\text { R.V.H. Grade II } \\
\text { R.V.H. Grade II }\end{array}$ & $\begin{array}{c}\text { Sustained } \\
\text { Sustained }\end{array}$ \\
\hline
\end{tabular}

TABLE III

Mitral Stenosis

\begin{tabular}{|c|c|c|c|c|c|}
\hline Case No. & $\begin{array}{l}\text { R.V. pressure } \\
\text { (mm. Hg) }\end{array}$ & $\begin{array}{l}\text { P.V.R. } \\
\text { (units) }\end{array}$ & Chest radiography & Electrocardiogram & $\begin{array}{l}\text { Left parasternal } \\
\text { impulse }\end{array}$ \\
\hline 1 & $29 / 0$ & $2 \cdot 5$ & Pulmonary venous & R.V.H. Grade I & Normal \\
\hline 2 M.S. (M.I.) & $\begin{array}{l}35 / 2 \\
37 / 0\end{array}$ & $1 \cdot 5$ & $\begin{array}{l}\text { Normal } \\
\text { R.V.+ }\end{array}$ & $\begin{array}{l}\text { No R.V.H. } \\
\text { No R.V.H. }\end{array}$ & $\begin{array}{l}\text { Normal } \\
\text { Sustained }\end{array}$ \\
\hline 4 & $38 / 0$ & & R.V. + & No R.V.H. & Normal \\
\hline 5 M.S. (M.I.) & 44/17 (P.A.) & $1 \cdot 7$ & R.V.+ & R.V.H. Grade I & Sustained \\
\hline 6 M.S. (M.I.) & $47 / 4$ & & R.V.t & R.V.H. Grade I & Sustained \\
\hline 7 M.S. (M.I.) & $57 / 7$ & & R.A.t+ & R.V.H. Grade I & Sustained \\
\hline 8 & 80/45 (P.A.) & & $\begin{array}{l}\text { R.V. }+ \text { L.A. }+ \\
\text { R.A. }+\end{array}$ & R.V.H. Grade II & Sustained \\
\hline
\end{tabular}

P.V.R., pulmonary vascular resistance.

stenosis and 4 had stenosis with insignificant mitral incompetence. Three patients had a normal left parasternal impulse. In these 3 the right ventricular systolic pressure was below $40 \mathrm{~mm} . \mathrm{Hg}$ and the electrocardiogram was normal or showed Grade I right ventricular hypertrophy. In 4 of the 5 patients with a sustained impulse the right ventricular systolic pressure was $45 \mathrm{~mm}$. $\mathrm{Hg}$ or more; in the fifth the pressure was $37 \mathrm{~mm}$. Hg. All these 5 patients had evidence of right ventricular hypertrophy in the chest radiograph and all but one in the electrocardiogram. Patients with significant mitral regurgitation will be discussed later in the group with biventricular hypertrophy.

Two other patients with pulmonary hypertension were studied: in one the diagnosis was primary pulmonary hypertension and in the other chronic cor pulmonale from chronic bronchitis. Both these cases had right ventricular hypertrophy in the chest radiograph and electrocardiogram: both showed a sustained left parasternal impulse.

\section{Group 2: Biventricular Hypertrophy}

(a) Mitral Regurgitation. There were 10 patients judged to have dominant mitral regurgitation, with biventricular hypertrophy from associated pulmonary hypertension. A further 4 were studied in whom mitral regurgitation was not complicated by pulmonary hypertension. All the patients with complicating pulmonary hypertension had a sustained left parasternal impulse in addition to a sustained apical impulse from left ventricular hypertrophy. However, 2 of the 4 patients without clinical evidence of pulmonary hypertension also had a sustained impulse at both apex and left sternal edge (Table IV) and in 1 of these 2, cardiac catheterization was performed, confirming 
normal right ventricular pressure. No direct correlation, therefore, could be made in these patients with mitral incompetence between a sustained left parasternal impulse and the presence of right ventricular hypertrophy. The reason for the sustained left parasternal impulse in the 2 patients without right ventricular hypertrophy was thought to be enlargement of the left ventricle to the right so as to underlie the parasternal region where the impulse is recorded (Deliyannis et al., 1964); angiocardiography in one of the patients confirmed that the enlarged left ventricle underlay the left parasternal impulse.

The amplitude of the ejection beat in this group was very striking. In 6 of the patients it was greater than $10 \mathrm{~mm}$. in height and the average deflection for the whole group was $10.7 \mathrm{~mm}$., compared with an average of $3.6 \mathrm{~mm}$. in the normal subjects.

(b) Ventricular Septal Defect. Twelve patients with biventricular hypertrophy from ventricular septal defect, complicated by pulmonary hypertension, were studied. In addition, a further,

TABLE IV

MITRAL INCOMPETENCE

\begin{tabular}{|c|c|c|c|}
\hline Case No. & $\begin{array}{l}\text { R.V. pressure } \\
(\mathrm{mm} . \mathrm{Hg})\end{array}$ & $\begin{array}{l}\text { Chest radiograph } \\
\text { and } \\
\text { electrocardiogram }\end{array}$ & $\begin{array}{l}\text { Left parasternal } \\
\text { impulse }\end{array}$ \\
\hline $\begin{array}{r}1 \\
2 \\
3 \\
4 \\
5 \\
6 \\
7 \\
8 \\
9 \\
10 \\
11 \\
12 \\
13 \\
14\end{array}$ & $\begin{array}{l}26 / 7 \\
35 / 0 \\
38 / 0 \\
53 / 3 \\
57 / 34 \text { (P.A.) } \\
70 / 0 \\
106 / 14\end{array}$ & $\begin{array}{l}\text { Borderline normal } \\
\text { L.V.H. } \\
\text { L.V.H. } \\
\text { L.V.H. } \\
\text { L.V.H. and R.V.H. } \\
\text { L.V.H. and R.V.H. } \\
\text { L.V.H. and R.V.H. } \\
\text { L.V.H. and R.V.H. } \\
\text { L.V.H. and R.V.H. } \\
\text { L.V.H. and R.V.H. } \\
\text { L.V.H. and R.V.H. } \\
\text { L.V.H. and R.V.H. } \\
\text { L.V.H. and R.V.H. } \\
\text { L.V.H. and R.V.H. }\end{array}$ & $\begin{array}{l}\text { Normal } \\
\text { Normal } \\
\text { Sustained } \\
\text { Sustained } \\
\text { Sustained } \\
\text { Sustained } \\
\text { Sustained } \\
\text { Sustained } \\
\text { Sustained } \\
\text { Sustained } \\
\text { Sustained } \\
\text { Sustained } \\
\text { Sustained } \\
\text { Sustained }\end{array}$ \\
\hline
\end{tabular}

TABLE V

Ventricular Septal Defect

\begin{tabular}{|c|c|c|c|c|}
\hline Case & $\begin{array}{l}\text { R.V. pressure } \\
(\mathrm{mm} . \mathrm{Hg})\end{array}$ & $\begin{array}{l}\text { Pulmonary- } \\
\text { systemic flow } \\
\text { ratio }\end{array}$ & $\begin{array}{c}\text { Chest radiograph } \\
\text { and } \\
\text { electrocardiogram }\end{array}$ & $\begin{array}{l}\text { Left parasternal } \\
\text { impulse }\end{array}$ \\
\hline $\begin{array}{r}1 \\
2 \\
3 \\
4 \\
5 \\
6 \\
7 \\
8 \\
9 \\
10 \\
11 \\
12 \\
13 \\
14 \\
15\end{array}$ & $\begin{array}{l}32 / 0 \\
32 / 4 \\
40 / 0 \\
45 / 10 \\
50 / 0 \\
58 / 0 \\
60 / 0 \\
60 / 0 \\
66 / 12 \\
70 / 0 \\
80 / 5 \\
92 / 3-7 \\
98 / 12\end{array}$ & $\begin{array}{r}1 \cdot 7: 1 \\
1 \cdot 3: 1 \\
1 \cdot 7: 1 \\
1 \cdot 5: 1 \\
1 \cdot 6: 1 \\
4: 1 \\
1 \cdot 1: 1 \\
1 \cdot 7: 1 \\
1 \cdot 5: 1\end{array}$ & $\begin{array}{l}\text { L.V.H. } \\
\text { L.V.H. } \\
\text { L.V.H. } \\
\text { L.V.H. and R.V.H. } \\
\text { L.V.H. and R.V.H. } \\
\text { L.V.H. and R.V.H. } \\
\text { L.V.H. and R.V.H. } \\
\text { L.V.H. and R.V.H. } \\
\text { L.V.H. and R.V.H. } \\
\text { L.V.H. and R.V.H. } \\
\text { L.V.H. and R.V.H. } \\
\text { L.V.H. and R.V.H. } \\
\text { L.V.H. and R.V.H. } \\
\text { L.V.H. and R.V.H. } \\
\text { L.V.H. and R.V.H. }\end{array}$ & $\begin{array}{l}\text { Normal } \\
\text { Normal } \\
\text { Overacting } \\
\text { Sustained (bifid) } \\
\text { Overacting } \\
\text { Sustained (bifid) } \\
\text { Sustained (bifid) } \\
\text { Normal } \\
\text { Overacting } \\
\text { Sustained (bifid) } \\
\text { Sustained (bifid) } \\
\text { Normal } \\
\text { Sustained (bifid) } \\
\text { Sustained (bifi) } \\
\text { Overacting }\end{array}$ \\
\hline
\end{tabular}




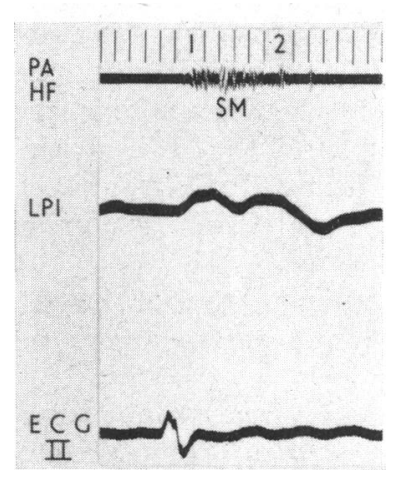

FIG. 5.-Bifid left parasternal impulse (LPI) in ventricular septal defect with pulmonary hypertension $(\mathrm{RVP}=70 / 0 \mathrm{~mm}$. $\mathrm{Hg}$; pulmonary systemic flow ratio $=1 \cdot 7: 1)$. $\mathrm{PA}, \mathrm{HF}=$ pulmonary area, high frequency; 1 and $2=$ first and second heart sounds; SM=systolic murmur; ECG II=electrocardiogram lead II. biventricular hypertrophy and increased flow through both ventricles.

The bifid type of sustained left parasternal impulse was only met in ventricular septal defect with pulmonary hypertension. Though the outward systolic movement was sustained up to or beyond the second heart sound, it was interrupted by an inward movement in mid-systole (Fig. 5). We were able to study a most remarkable patient with a bifid impulse who had a large sternal defect so that the right ventricular outflow tract and the main pulmonary artery were widely exposed (Fig. 6). This patient's right ventricular systolic pressure was at systemic level. There was no detectable

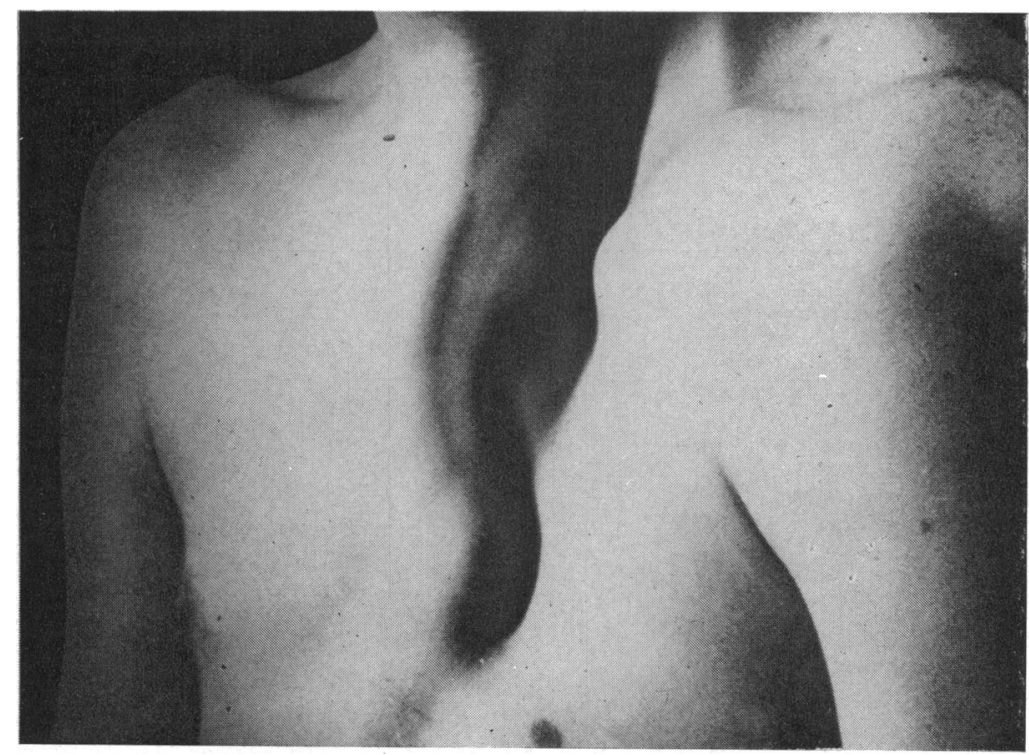

FIG. 6.-Case R.L. Photograph of præcordium with sternal defect in patient with ventricular septal defect and pulmonary hypertension. 


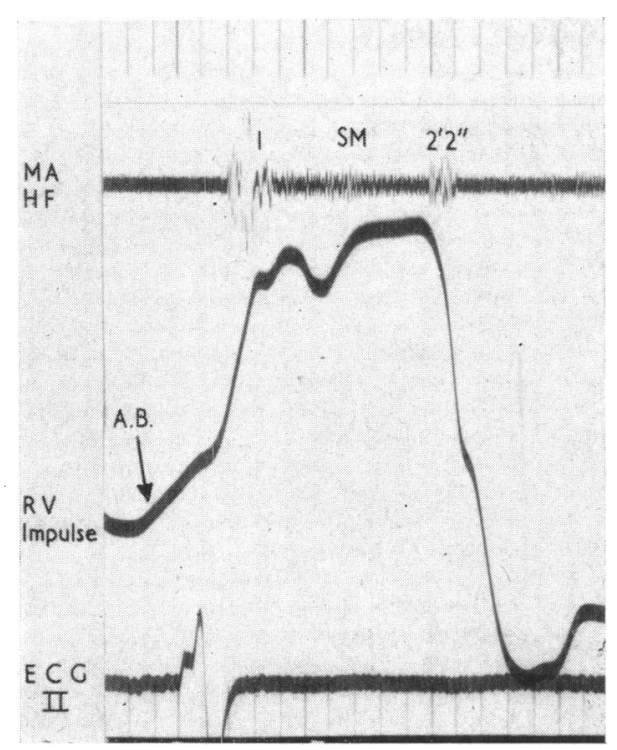

FIG. 7.-Case R.L. Cardiogram of impulse in sternal defect over right ventricular outflow tract. Bifid sustained impulse. $\mathrm{AB}=$ atrial beat; $\mathrm{MA}, \mathrm{HF}=$ mitral area, high frequency; 1 and $2^{\prime} 2^{\prime \prime}=$ first sound and split second sound; $\mathrm{SM}=$ systolic murmur; ECG II=electrocardiogram lead II.

shunt. The impulse cardiogram was recorded directly over the pulmonary artery and the right ventricular outflow tract through the sternal defect (Fig. 7). The impulse over the pulmonary artery and the right ventricular outflow tract was felt to be very bifid. The timing of the notch in the bifid impulse coincided with a dicrotic notch in the pressure tracing from the right ventricle and may have been due to the same cause (Fig. 8). Shanahan et al. (1960) describe a form of right ventricular pressure tracing, only met in Fallot's tetralogy and large ventricular septal defects, in which there is a high pressure and plateau curve that usually shows a distinct notch at the beginning of the plateau.

The one patient with a patent ductus arteriosus and severe pulmonary hypertension had a sustained impulse.

\section{Left Parasternal Impulse in Right Atrial Hypertrophy}

We have already mentioned that an atrial beat at the left sternal edge was found more frequently in pulmonary stenosis and atrial septal defect than in health. Its amplitude, however, seldom exceeded the upper limit of normal. In certain forms of cardiomyopathy involving the right heart, on the other hand, a giant atrial beat was felt and recorded (Mounsey, 1959), which corresponded with the giant " $a$ " wave in the jugular venous pulse. It was usually appreciated by the hand as a distinct double impulse (Mounsey, 1959; Paré et al., 1961; Wigle, Heimbecker, and Gunton, 1962; Cohen et al., 1964), thus contrasting with the gentle presystolic atrial beat felt in simple ventricular hypertrophy. In the impulse cardiogram at the left sternal edge it was the dominant impulse, dwarfing the ventricular impulse (Fig. 9). A giant atrial beat dwarfing the ventricular impulse was noted in 5 out of 10 patients with various forms of cardiomyopathy and is characteristic and possibly pathognomonic of hypertrophic cardiomyopathy with diminished compliance of the ventricles. A more detailed study of this group of patients is in progress (Nagle et al., in preparation). 


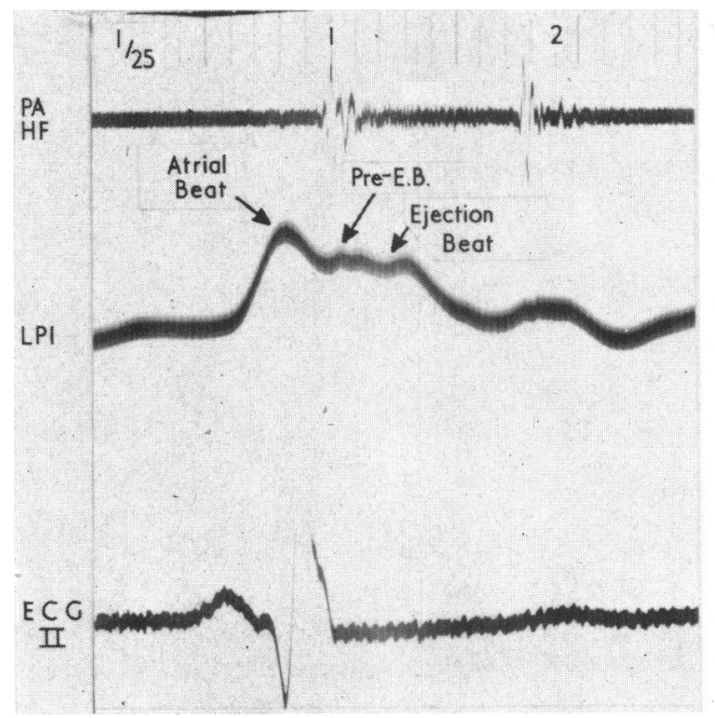

FIG. 9.-Giant atrial beat, dwarfing ventricular impulse in cardiomyopathy. Pre-ejection beat (Pre-E.B.) and ejection beat (E.B.) of smaller amplitude than atrial beat in left parasternal impulse (LPI). PA, HF = pulmonary area, high frequency; 1 and $2=$ first and second heart sounds; $\mathrm{SM}=$ systolic murmur; ECG II=electrocardiogram lead II.

\section{Discussion}

The movements at the left parasternal region which accompany ventricular systole are less easy to appreciate than those at the cardiac apex: their amplitude is usually smaller, and there is less relative movement of one part of the chest wall with another. What one appreciates with the hand is the total displacement of a wide area of chest wall, and it is important that the instrument used to record this movement should be one that responds to total displacement. Indeed, workers using the upturned bell type of instrument which is held on or strapped to the chest wall and which records relative movement, have recorded very little parasternal movement. Thus Mackenzie (1902) thought that right ventricular systole always produced depression of the chest wall. Dressler (1937) was the first to suggest the importance of recording absolute movement and arranged his instrument in a fixed support attached to the bed. He showed that in normal subjects there might be systolic depression at the left sternal edge, but in patients with right ventricular hypertrophy resulting from severe mitral stenosis there was a marked systolic outward movement. More recently Eddleman and Thomas (1959), using a similar instrument, have shown that the outward movement is sustained throughout ventricular ejection in patients with increased right ventricular pressure loads, but not in those with increased right ventricular flow.

The clinical sign of a left parasternal lift in right ventricular hypertrophy is now widely recognized. Wood (1956) distinguished the steady heave that occurs in pulmonary hypertension and pulmonary stenosis from the more tumultuous hyperdynamic lift of atrial septal defect. The fact that a parasternal impulse can be felt in many normal subjects is not so generally appreciated. With our instrument which records absolute displacement of the chest wall, we recorded a parasternal impulse in 20 normal subjects, though it was only easily palpable in 15 of them. In two-thirds of the cases this consisted of an outward movement, usually small, followed by retraction in late systole; in the rest, inward movement only occurred. The outward movement only lasted for up to the first two-thirds of systole.

Our study enabled us to assess the reliability of an abnormal left parasternal impulse as a clinical sign of right heart disease. In patients with pure right ventricular hypertrophy an impulse consisting 
of a sustained outward movement lasting up to or beyond the second heart sound is a reliable sign, being found in 15 out of 18 patients with hypertrophy and never in patients with mild disease without a significant hypertrophy. The overacting or "hyperdynamic" impulse of atrial septal defect is one of increased amplitude but normal contour. We have found it indistinguishable from that met in children and in thin or anxious adults. The only patient with an atrial septal defect who had a sustained impulse was one with complicating pulmonary hypertension.

In the group of patients where biventricular hypertrophy may be present, a sustained left parasternal impulse was found to be a less reliable sign of right ventricular hypertrophy. In two patients with mitral regurgitation but without pulmonary hypertension a sustained impulse was found: it was thought to be due to enlargement of the left ventricle which encroached on the position normally occupied by the right. Conversely, 5 out of 12 patients with ventricular septal defect complicated by pulmonary hypertension had a normal or overacting impulse; only 8 had a sustained impulse, which in 7 was of a bifid form. The special combination of varying degrees of left-to-right interventricular shunt and of pulmonary hypertension may account for the poor correlation between a sustained left parasternal impulse and right ventricular hypertrophy in ventricular septal defect.

Patients with mitral incompetence and pulmonary hypertension commonly have a sustained parasternal impulse of great amplitude. These patients often have a very large left atrium, and it is possible that this acts as a distensible cushion which lifts the heart forward against the sternum.

Differentiation of right and left ventricular impulses is usually made on the site of the impulse, those at the left sternal edge reflecting the right ventricle and those at the apex reflecting the left. Deliyannis et al. (1964) have shown that, with great right or left ventricular enlargement, either ventricle may encroach on the position normally occupied in health by the other. Thus the right ventricle may produce a widespread præcordial impulse, extending from the left sternal edge to the apex. Similarly the left ventricle may be responsible for an impulse at the apex which spreads round to the left sternal edge. As a result of the varying relation of the underlying ventricles to the selected areas on the præcordium, it may sometimes be difficult to distinguish between great enlargement of one ventricle and biventricular hypertrophy.

The finding of a sustained left parasternal impulse when there is underlying right ventricular hypertrophy parallels the sustained apical impulse of left ventricular hypertrophy caused by systemic hypertension (Beilin and Mounsey, 1962) and aortic and mitral valve disease (Davie et al., 1962; Gillam, 1963). An easy way of appreciating this physical sign is to auscultate at the same time as palpating. In this way the prominent overacting impulse felt in some normal subjects and in patients with an atrial septal defect may easily be distinguished at the bedside from the sustained impulse of pulmonary hypertension.

\section{SUMMARY}

The left parasternal impulse has been recorded, using an instrument which measures total displacement of the chest wall, in 20 normal subjects and 71 patients with congenital or acquired disease of the right ventricle. The detailed pattern of normal and abnormal impulses has been described. There were three main groups: the normal, the overacting, and the sustained.

In most normal subjects there was an outward movement of the chest wall in the left parasternal area during early systole, followed by retraction in late systole; in some an inward movement only occurred. An overacting impulse of unusually large amplitude but normal contour was seen in children and in sternal depression. Healthy hearts, therefore, showed either a normal or overacting left parasternal impulse.

Most patients with an atrial septal defect without pulmonary hypertension showed an overacting impulse reflecting the augmented right ventricular stroke output.

Four-fifths of the patients with marked right ventricular hypertrophy from right ventricular hypertension had a sustained impulse lasting up to the time of the second heart sound or beyond; one-fifth had an overacting or normal impulse. A bifid sustained impulse was noted in some cases of ventricular septal defect with pulmonary hypertension. The presence of a sustained left para- 
sternal impulse was found to be a reliable sign of hypertrophy of the right ventricle, except in rare cases where an enlarged left ventricle underlay this area of the præcordium.

An atrial beat at the left sternal edge, accompanying atrial systole, was seen more often in right ventricular hypertrophy with associated right atrial hypertrophy than in health. A giant atrial beat, dwarfing the succeeding ventricular impulse, appreciated by the hand as a double impulse, was found to be characteristic of one form of cardiomyopathy with diminished compliance of the ventricles.

We would like to thank Professor J. F. Goodwin, Dr. J. P. Shillingford, and Dr. C. T. Dollery for permission to study their patients, and Dr. Ivor Gabe for helpful advice. We are also grateful to Mr. Peter Burgess and Miss Jean Powell for technical assistance.

\section{REFERENCES}

Beilin, L., and Mounsey, J. P. D. (1962). The left ventricular impulse in hypertensive heart disease. Brit. Heart J., 24, 409.

Cohen, J., Effat, H., Goodwin, J. F., Oakley, C. M., and Steiner, R. E. (1964). Hypertrophic obstructive cardiomyopathy. Brit. Heart J., 26, 16.

Davie, J. C., Langley, J. O., Dodson, W. H., and Eddleman, E. E. (1962). Clinical and kinetocardiographic studies of paradoxical precordial motion. Amer. Heart J., 63, 775.

Deliyannis, A. A., Gillam, P. M. S., Mounsey, J. P. D., and Steiner, R. E. (1964). The cardiac impulse and the motion of the heart. Brit. Heart J., 26, 396.

Dressler, W. (1937). Pulsations of the wall of the chest. Arch. intern. Med., 60, 225, 437, 441, 654, and 663.

Eddleman, E. E., and Thomas, H. D. (1959). The recognition and differentiation of right ventricular pressure and flow loads. Amer. J. Cardiol., 4, 652.

Gillam, P. M. S. (1963). The cardiac impulse in health and disease. Proc. roy. Soc. Med., 56, 761.

Goodwin, J. F., and Abdin, Z. H. (1959). The cardiogram of congenital and acquired right ventricular hypertrophy. Brit. Heart J., 21, 523.

Mackenzie, J. (1902). The Study of the Pulse, Arterial, Venous, and Hepatic, and of the Movements of the Heart. Pentland, Edinburgh and London.

Mounsey, J. P. D. (1959). Precordial pulsations in relation to cardiac movement and sounds. Brit. Heart J., $21,457$.

Nagle, R. E., Boicourt, O. W., Gillam, P. M. S., and Mounsey, J. P. D. The cardiac impulse in cardiomyopathy. In preparation.

Paré, J. A. P., Fraser, R. G., Pirozynski, W. J., Shanks, J. A., and Stubington, D. (1961). Hereditary cardiovascular dysplasia. A form of familial cardiomyopathy. Amer. J. Med., 31, 37.

Shanahan, R., Myers, G. S., Del Campo, E., Freidlich, A. I., and Scannell, G. (1960). Right ventricular pressure curves in congenital and acquired heart disease. 'Brit. Heart J., 22, 457.

Wigle, E. D., Heimbecker, R. O., and Gunton, R. W. (1962). Idiopathic ventricular septal hypertrophy causing muscular subaortic stenosis. Circulation, 26, 325 .

Wood, P. H. (1956). Diseases of the Heart and Circulation, 2nd ed. Eyre and Spottiswoode, London. 